\title{
Ultrasound measurements versus invasive intracranial pressure measurement method in patients with brain injury: a retrospective study
}

\author{
Jing Zhou, Jing Li, Tiantian Ye and Yanrong Zeng ${ }^{*}$ (D)
}

\begin{abstract}
Background: The invasive method for intracranial pressure measurement is 'gold standard' but not always feasible because the intraventricular catheter/ intraparenchymal micro transducer used in the measurement of intracranial pressure measurement may cause complications. Imaging modalities with clinical examination protocol have a lack of specificity and accuracy. The objective of the study was to compare the accuracy of diagnostic parameters of ultrasound measurements in patients with brain injury underwent invasive intracranial pressure measurement method.
\end{abstract}

Methods: Data of invasive intracranial pressure measurement method and ultrasound measurements of 185 patients with brain injury who required admission diagnosis were included in the analysis. Pearson correlation was tested for diagnostic parameters. Logistical regression analysis was performed for diagnostic parameters of death patients to evaluate independent parameter of mortality.

Results: Straight sinus flow velocities, middle cerebral artery flow velocities, and optic nerve sheath diameter were correlated with intracranial pressure $(p<0.0001$ for all). Arterial blood pressure $(p=0.127)$ and middle cerebral artery pulsatility index $(p=0.06)$ were not correlated with intracranial pressure. A total of 47 patients died during the study period. Intracranial pressure $(p=0.015)$ and optic nerve sheath diameter $(p=0.035)$ were found to be independent predictor of mortality.

Conclusions: Ultrasound measurement especially optic nerve sheath diameter can be successfully used instead of invasive intracranial pressure measurement method in patients with brain injury.

Level of evidence: III.

Keywords: Blood flow velocities, Brain injury, Intracranial pressure, Optic nerve sheath diameter, Pulsatility index, Ultrasound

\section{Background}

Intracranial hypertension is a deadly complication and one of the contributing factor in secondary brain injury because its intensity and duration are associated with a fatal outcome [1].

Imaging modalities with clinical examination protocol have a lack of specificity [2] and insufficient accuracy [3]. Therefore, the invasive intracranial pressure measurement

\footnotetext{
* Correspondence: YeddaGenevieveoJx@yahoo.com

Department of Ultrasound, Beijing Luhe Hospital, Affiliated to Capital Medical University, Beijing 101149, China
}

method is recommended [4] but a multicenter, controlled trial on patients with brain injury comparing care focused on imaging and clinical examination with care focused on maintaining intracranial pressure at $20 \mathrm{mmHg}$ or less has found no significant differences [2].

The use of an intraventricular catheter/ intraparenchymal micro transducer may cause complications like infection or hemorrhage [5]. Therefore, the invasive intracranial pressure measurement method is only used in severe traumatic brain injury when systemic complications are absent [6]. When invasive intracranial pressure measurement method 
is contraindicated, imaging modalities with clinical examination would be preferred [4]. A prospective, observational study on patients with traumatic brain injuries recommended ocular sonography as a screening test for raised intracranial pressure measurements [7]. A retrospective study suggested transcranial Doppler for measurement of intracranial pressure [8]. Two-depth transcranial Doppler has better diagnostic reliability for intracranial pressure measurements $[9,10]$.

The primary aim of the retrospective study was to compare the accuracy of diagnostic parameters of ultrasound measurements in patients with brain injury underwent invasive intracranial pressure measurement method. The secondary endpoint of the study was to evaluate independent diagnostic parameters for mortality of patients in a Chinese setting.

\section{Methods}

\section{Inclusion criteria}

Patients age 18 years or older with severe traumatic brain injury, intraparenchymal hemorrhage, aneurysmal subarachnoid hemorrhage, or stroke (decision of neurosurgeon) were included in the analysis. Among these patients, who required sedation, intracranial pressure monitoring or mechanical ventilation with an admission diagnosis were included in the analysis.

\section{Exclusion criteria}

Patients were excluded from the analysis who had optic nerve injuries, skull base fracture (with cerebrospinal fluid leaks), an ocular pathology, inaccessible ultrasound windows, and no radiological or clinical susceptibility of cerebral venous vasospasm or thrombosis. Patients whose intracranial pressure mean values changed $>2$ $\mathrm{mmHg}$ during ultrasound measurements and who had a history of glaucoma were not included in the analysis.

\section{Clinical management of patients}

Patients were put on propofol (a continuous infusion) and the muscle relaxant (atracurium) was given when necessary. Mechanical ventilation was adjusted to maintain normocapnia (partial pressure of carbon dioxide: $38 \pm 2 \mathrm{mmHg}$ ) and adequate oxygenation (peripheral oxygen saturation $\geq 91 \%$ ). The adequate cerebral perfusion pressure had been maintained $\geq 61 \mathrm{mmHg}$ by norepinephrine, vasopressors, and normal saline [11]. As per institutional guidelines, intracranial hypertension had been treated by optimizing arterial blood pressure and using hyperosmolar fluids and sedation infusion.

\section{Invasive intracranial pressure measurement method}

Intracranial pressure had been measured by intensive care physician (minimum 10-years of experience) of institutes using $1.3 \mathrm{~mm}$ Tunnelling intraparenchymal probe (3PN, Spiegelberg GmbH \& Co. KG, Hamburg, Germany) or a catheter inserted into the ventricles of brain and was connected to an external drainage and pressure transducer and system $\left(\mathrm{Camino}^{\circ}\right.$, Integra ${ }^{\circ} \mathrm{Life}$ Sciences Corporation, Plainsboro, NJ, USA). Admission Glasgow Coma Scale, demographical characteristics, comorbidities, severity and mechanism of brain injuries, and discharge Glasgow Outcome Scale were recorded for each patient [12].

\section{Ultrasound measurements}

Ultrasound measurements had been performed by ultrasound equipment (GE Healthcare, Beijing, China) by ultra-sonographers of the institutes (blinded regarding the results of the invasive intracranial pressure measurement method and minimum 10-years of experience). The mean values of five individual measurements were considered in the analysis. Venous transcranial Doppler measurements, optic nerve sheath diameter, and arterial transcranial doppler had been measured twice in a day from day $1-5$ at $50-80 \mathrm{~mm}$ optic nerve blood pressure (as accessible ultrasound windows).

\section{Venous transcranial Doppler measurements}

Arterial blood pressure, cerebral perfusion pressure, the partial pressure of carbon dioxide, diastolic $\left(\mathrm{FV}_{\mathrm{d}}\right)$, mean $\left(\mathrm{FV}_{\mathrm{m}}\right)$, and systolic $\left(\mathrm{FV}_{\mathrm{s}}\right)$ middle cerebral artery flow velocities, $F V_{d}, F V_{m}$, and $F V_{s}$ straight sinus flow velocities were recorded by $2 \mathrm{MHz}$ linear probes (GE Healthcare, Beijing, China) on the straight sinus through an occipital and transforaminal bone window [5].

\section{Optic nerve sheath diameter measurements}

Optic nerve sheath diameter was recorded by $7.5 \mathrm{MHz}$ linear probes (GE Healthcare, Beijing, China) with the lowest possible acoustic power. The gel was applied on

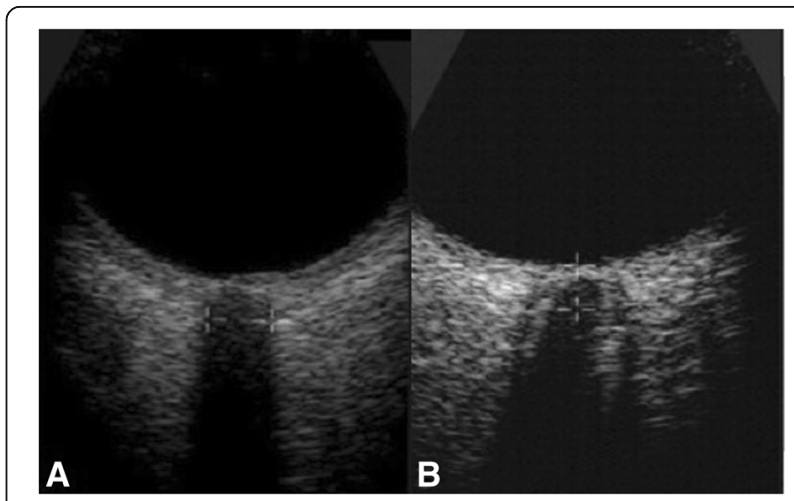

Fig. 1 Ultrasound measurements of the axial plane of the right eye. a Optic nerve sheath of a patient with normal intracranial pressure. No subarachnoid space around the optic nerve. b Optic nerve sheath of a patient with high intracranial pressure. Significant subarachnoid space around the optic nerve 
the surface of eyelids. The probe was oriented $30^{\circ}$ on both closed eyes of the patients with the head elevated to $30^{\circ}$ in the supine position at approximately $30^{\circ}$ on the length of the plane and at the horizontal surface. The measurements of axial and sagittal planes of both eyes had been made such that the visible widest diameter behind the retina was $2.8 \mathrm{~mm}$ (Fig. 1) [13].

\section{Arterial transcranial Doppler measurement}

$2 \mathrm{MHz}$ linear probe (GE Healthcare, Beijing, China) was used to measure arterial transcranial Doppler measurement in the same supine position of the patients. It was performed bilaterally on middle cerebral artery using temporal window [14].

Events of mortality were collected from institutional records.

\section{Statistical analysis}

InStat GraphPad Software, San Diego, IL, USA was used for statistical analysis. Pearson correlation was tested for diagnostic parameters. Logistical regression analysis was performed for diagnostic parameters among the data of death patients. Inter-rater reliability was evaluated by intraclass correlation coefficient (>0.8: optimal, 0.7-0.8: strong, 0.5-0.69: moderate, 0.3-0.49: fair, <0.3: poor), calculated by a two-way random effects model in Stata 12.1 software (StataCorp, College Station, TX, USA) [15]. The results were considered significant at $95 \%$ of confidence level.

\section{Results \\ Enrollment}

Data of patients who required intracranial pressure monitoring or mechanical ventilation with an admission diagnosis from 12 February 2017 to 1 January 2019 of the Beijing Luhe Hospital, Affiliated to Capital Medical University, Beijing, China, and referring hospitals were reviewed. Among the available patients' records, 15 patients had optic nerve injuries, 41 had skull base fracture, 13 had a known history of ocular pathology, 40 had

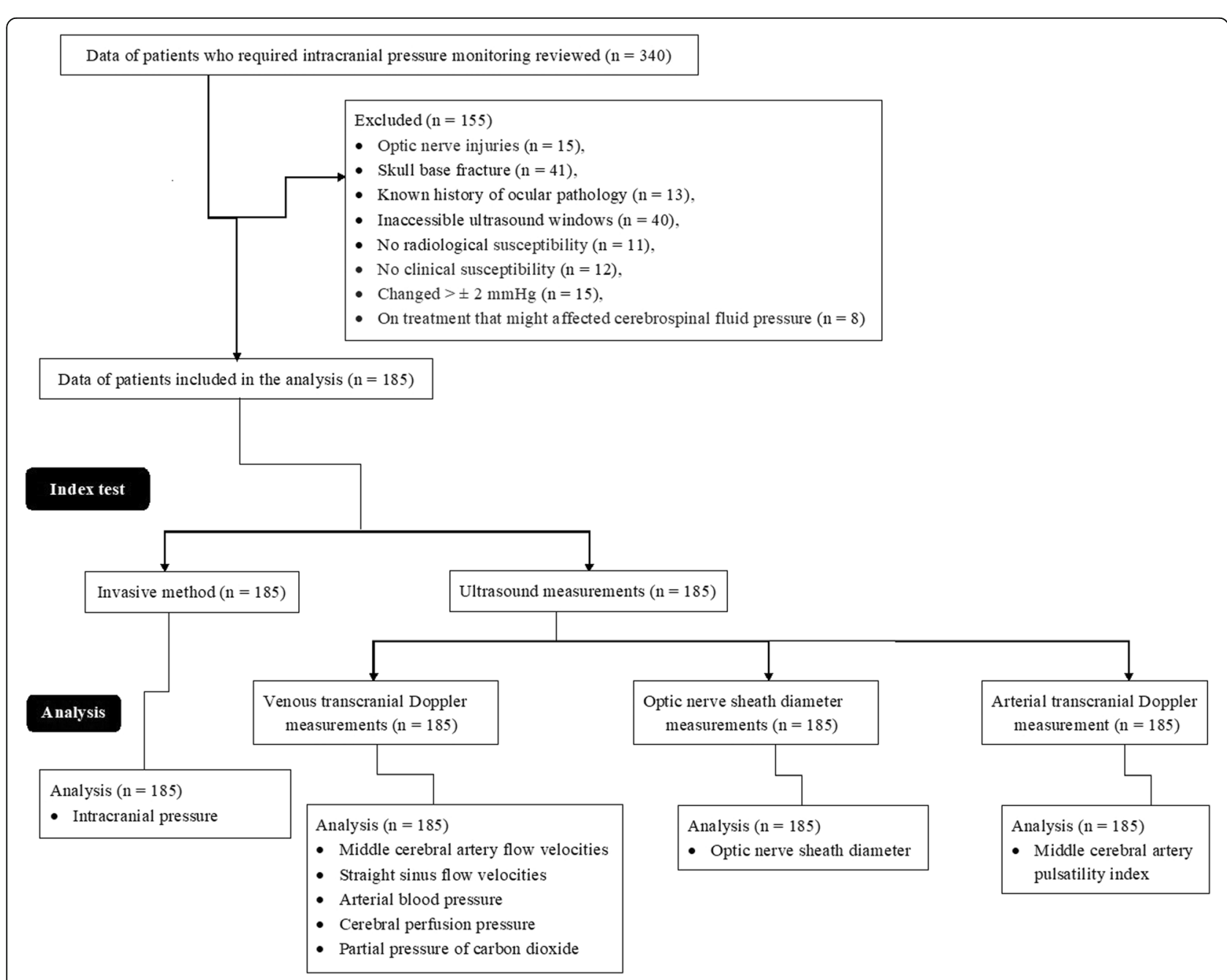

Fig. 2 Flowchart of the analysis 
inaccessible ultrasound windows, 11 had no radiological susceptibility of cerebral venous thrombosis, and $12 \mathrm{had}$ no clinical susceptibility of cerebral thrombosis. Therefore, these data were excluded from the analysis. Also, 8 patients were on treatment that might affect cerebrospinal fluid pressure, so excluded from the analysis. Even, 15 patients had reported more than $\pm 2 \mathrm{mmHg}$ changes in mean values of intracranial pressure during ultrasound measurements. Therefore, these data were also excluded from the analysis. Data of invasive intracranial pressure measurement method and ultrasound measurements of 185 patients were included in the analysis. Flow chart of the study is presented in Fig. 2.

\section{Characteristics of patients}

The minimum admission Glasgow Coma Scale of the enrolled patients was 4 . The other demographical and clinical characteristics of enrolled patients are presented in Table 1.

\section{Diagnostic parameters}

Straight sinus flow velocities, middle cerebral artery flow velocities, and optic nerve sheath diameter were correlated with intracranial pressure $(p<0.0001$ for all). Arterial blood pressure $(p=0.127)$ and middle cerebral artery pulsatility index $(p=0.06)$ were not correlated with intracranial pressure (Table 2). Inter-rater reliability had strong agreement (intraclass correlation coefficient = 0.71) among ultra-sonographers.

\section{Prediction of mortality}

From institutional records, it was found that 34 patients died during hospitalization and 13 patients died during the follow-up period. No significant association was observed between intracranial pressure and neuropsychological and functional outcomes during hospitalization and follow-up period for survived patients. Multivariate analysis was performed among diagnostic data of death patients. Intracranial pressure $(p=0.015)$ and optic nerve sheath diameter $(p=0.035)$ were found to be independent predictor of mortality (Table 3 ).

\section{Discussion}

\section{Intracranial pressure measurement}

In the study, all the enrolled patients required admission diagnosis and subjected to measure intracranial pressure. Also, elevated intracranial pressure was found a significant parameter of death $(p=0.015)$ and no association between intracranial pressure and neuropsychological outcome during follow-up period among survivors. The results of the study were consistent with prospective cohort studies $[1,5]$ and a multicenter, controlled trial [2]. The pathophysiological events and elevated intracranial pressure can
Table 1 Demographical and clinical characteristics of enrolled patients

\begin{tabular}{|c|c|c|}
\hline \multicolumn{2}{|l|}{ Characteristics } & \multirow{2}{*}{$\begin{array}{l}\text { Value } \\
185\end{array}$} \\
\hline Data of patients included in the analy & & \\
\hline \multirow[t]{2}{*}{ Gender } & Male & $86(47)$ \\
\hline & Female & $99(53)$ \\
\hline \multirow[t]{3}{*}{ Age (years) } & Minimum & 38 \\
\hline & Maximum & 68 \\
\hline & Mean \pm SD & $52.42 \pm 4.53$ \\
\hline \multicolumn{2}{|l|}{ Weight (kg) } & $58.42 \pm 4.59$ \\
\hline \multicolumn{2}{|l|}{ Height (cm) } & $161 \pm 6$ \\
\hline \multicolumn{3}{|l|}{ Pathology } \\
\hline \multicolumn{2}{|l|}{ Traumatic brain injury } & $135(73)$ \\
\hline \multicolumn{2}{|l|}{ Intraparenchymal hemorrhage } & $38(21)$ \\
\hline \multicolumn{2}{|l|}{ Aneurysmal subarachnoid hemorrhage } & $12(6)$ \\
\hline \multicolumn{3}{|l|}{ Comorbidities } \\
\hline \multicolumn{2}{|l|}{ Asthma } & $19(10)$ \\
\hline \multicolumn{2}{|l|}{ Hypertension } & $18(10)$ \\
\hline \multicolumn{2}{|l|}{ Depression } & $35(19)$ \\
\hline \multicolumn{2}{|l|}{ Alcoholic } & $8(4)$ \\
\hline \multicolumn{2}{|l|}{ Smokers } & $15(8)$ \\
\hline \multicolumn{2}{|l|}{ History of myocardial infarction } & $3(2)$ \\
\hline \multirow[t]{3}{*}{ Admission Glasgow Coma Scale } & Maximum & 14 \\
\hline & Minimum & 4 \\
\hline & Median & 9 \\
\hline \multirow[t]{3}{*}{ Discharge Glasgow Outcome Scale } & Maximum & 5 \\
\hline & Minimum & 1 \\
\hline & Median & 3 \\
\hline \multicolumn{2}{|l|}{ Chest infection } & $29(16)$ \\
\hline \multicolumn{2}{|c|}{ Post-traumatic acute respiratory distress syndrome } & $6(3)$ \\
\hline \multicolumn{2}{|l|}{ Sepsis } & $5(3)$ \\
\hline \multicolumn{2}{|l|}{ Ventriculitis } & $2(1)$ \\
\hline
\end{tabular}

Categorial variables are represented as number (percentage) and continuous variables are represented as mean \pm SD or median

have effects on neuropsychological outcome in patients with brain injury [16]. Intracranial pressure is an independent predictor of death in patients with brain injury.

\section{Venous transcranial Doppler measurements}

Straight sinus flow velocities and middle cerebral artery flow velocities had a correlation with intracranial pressure, those were measured invasively but failed to predict mortality. The results of the study were consistent with the clinical study $[2,17]$ and with prospective observational study [5]. Increasing intracranial pressure leads to venous hemodynamic changes but strongly in the low-pressure venous compartment only [5]. Transcranial 
Table 2 Diagnostic parameters

\begin{tabular}{|c|c|c|c|c|c|}
\hline \multicolumn{2}{|l|}{ Characteristics } & \multirow{3}{*}{$\begin{array}{l}\text { Value } \\
185 \\
5\end{array}$} & \multirow{2}{*}{$\begin{array}{l}\text { (Pearson } \\
\text { correlation } \\
\text { coefficient) }\end{array}$} & \multirow{2}{*}{$\begin{array}{l}\text { Significant } \\
\text { range of ' } r \text { ' }\end{array}$} & \multirow[t]{2}{*}{$p$-value } \\
\hline Data of patients included in the analysis & & & & & \\
\hline \multirow[t]{3}{*}{ Intracranial pressure $(\mathrm{mmHg})$} & Minimum & & Reference & Reference & Reference \\
\hline & Maximum & 17 & & & \\
\hline & Mean \pm SD & $10.24 \pm 3.51$ & & & \\
\hline \multirow[t]{3}{*}{${ }^{a}$ Arterial blood pressure $(\mathrm{mmHg})$} & Minimum & 84 & 0.1125 & $0.2527-0.3233$ & 0.127 \\
\hline & Maximum & 101 & & & \\
\hline & Mean \pm SD & $90.61 \pm 5.29$ & & & \\
\hline \multirow[t]{3}{*}{ Cerebral perfusion pressure $(\mathrm{mmHg})$} & Minimum & 71 & 0.9527 & $0.9243-0.957$ & $<0.0001$ \\
\hline & Maximum & 88 & & & \\
\hline & Mean \pm SD & $78.13 \pm 4.58$ & & & \\
\hline \multirow[t]{3}{*}{ Partial pressure of carbon dioxide $(\mathrm{mmHg})$} & Minimum & 4.85 & 0.9027 & $0.872-0.9264$ & $<0.0001$ \\
\hline & Maximum & 5.95 & & & \\
\hline & Mean \pm SD & $5.24 \pm 0.27$ & & & \\
\hline \multirow[t]{3}{*}{ Straight sinus systolic flow velocity $(\mathrm{cm} / \mathrm{s})$} & Minimum & 23 & 0.8662 & $0.825-0.8982$ & $<0.0001$ \\
\hline & Maximum & 40 & & & \\
\hline & Mean \pm SD & $31.11 \pm 4.9$ & & & \\
\hline \multirow[t]{3}{*}{ Straight sinus diastolic flow velocity $(\mathrm{cm} / \mathrm{s})$} & Minimum & 12 & 0.5538 & $0.4451-0.6465$ & $<0.0001$ \\
\hline & Maximum & 18 & & & \\
\hline & Mean \pm SD & $13.47 \pm 1.31$ & & & \\
\hline \multirow[t]{3}{*}{ Straight sinus means flow velocity $(\mathrm{cm} / \mathrm{s})$} & Minimum & 15 & 0.9298 & $0.9072-0.947$ & $<0.0001$ \\
\hline & Maximum & 25 & & & \\
\hline & Mean \pm SD & $20.16 \pm 3.23$ & & & \\
\hline \multirow[t]{3}{*}{ Middle cerebral artery systolic flow velocity $(\mathrm{cm} / \mathrm{s})$} & Minimum & 95 & 0.8724 & $0.833-0.9031$ & $<0.0001$ \\
\hline & Maximum & 115 & & & \\
\hline & Mean \pm SD & $103.27 \pm 5.64$ & & & \\
\hline \multirow[t]{3}{*}{ Middle cerebral artery diastolic flow velocity $(\mathrm{cm} / \mathrm{s})$} & Minimum & 40 & 0.7681 & $0.7016-0.8214$ & $<0.0001$ \\
\hline & Maximum & 55 & & & \\
\hline & Mean \pm SD & $47.38 \pm 4.26$ & & & \\
\hline \multirow[t]{3}{*}{ Middle cerebral artery means flow velocity $(\mathrm{cm} / \mathrm{s})$} & Minimum & 60 & 0.9 & $0.8685-0.9243$ & $<0.0001$ \\
\hline & Maximum & 76 & & & \\
\hline & Mean \pm SD & $69.1 \pm 3.81$ & & & \\
\hline \multirow[t]{3}{*}{ Optic nerve sheath diameter (mm) } & Minimum & 4 & 0.8717 & $0.832-0.9025$ & $<0.0001$ \\
\hline & Maximum & 6 & & & \\
\hline & Mean \pm SD & $4.77 \pm 0.43$ & & & \\
\hline \multirow[t]{3}{*}{${ }^{\mathrm{a} M i d d l e ~ c e r e b r a l ~ a r t e r y ~ p u l s a t i l i t y ~ i n d e x ~}$} & Minimum & 0.85 & 0.1423 & $0.2134-0.2809$ & 0.06 \\
\hline & Maximum & 1.05 & & & \\
\hline & Mean \pm SD & $0.93 \pm 0.08$ & & & \\
\hline
\end{tabular}

Variables are represented as mean \pm SD

Pearson correlation was performed with intracranial pressure

A $p$ value less than 0.05 was considered significant

${ }^{a}$ Insignificant correlation with intracranial pressure

insonation difficulties and anatomical variations in cerebral veins were responsible for the poor performance of straight sinus and middle cerebral artery flow velocities to predict intracranial pressure [5]. Venous transcranial Doppler measurements are poorly developed method of diagnosis. 
Table 3 Multivariate analysis for prediction of mortality

\begin{tabular}{ll}
\hline Characteristics & $p$-value \\
\hline Data of patients included in the analysis & 47 \\
Intracranial pressure $^{\mathrm{a}}$ & 0.015 \\
Arterial blood pressure & 0.12 \\
Cerebral perfusion pressure & 0.072 \\
Partial pressure of carbon dioxide & 0.085 \\
Straight sinus systolic flow velocity & 0.062 \\
Straight sinus diastolic flow velocity & 0.067 \\
Straight sinus means flow velocity & 0.068 \\
Middle cerebral artery systolic flow velocity & 0.078 \\
Middle cerebral artery diastolic flow velocity & 0.086 \\
Middle cerebral artery means flow velocity & 0.082 \\
Optic nerve sheath diameter & \\
Middle cerebral artery pulsatility index & 0.035
\end{tabular}

A $p$ value less than 0.05 was considered significant

Data of survived patients were considered as the reference standard

${ }^{\mathrm{a}}$ Significant predictor of mortality

\section{Optic nerve sheath diameter measurements}

Optic nerve sheath diameter was found an individual parameter of death $(p=0.035)$ as well as had correlation $(p<0.0001)$ with intracranial pressure, those were measured invasively. The results of the study were consistent with prospective observational studies $[5,7,9,18]$ and a multicenter, controlled trial [2]. The optic nerve is surrounded by cerebrospinal fluid [7]. If cerebrospinal fluid pressure increases, there will be enlargement of the optic nerve sheath [5]. Even, measurement of optic nerve sheath diameter is a simple, accurate, safe, and quick method of diagnosis. Clinicians would prefer the measurements of optic nerve sheath diameter in their intensive care units for patients with brain injury.

\section{Arterial transcranial doppler measurement}

Middle cerebral artery pulsatility index had no correlation $(p=0.06)$ with intracranial pressure and was not independent parameter of death $(p=0.095)$. The results of the study were consistent with the clinical studies [5, 17] but not consistent with case report [19]. The possible justification is that in physiological parameters may affect pulsatility index [17] while intracranial pressure is independent parameter [20]. Even, intracranial pressure is a dynamic dimension that changes rapidly with time [7] and it is unclear whether or how pulsatility index would change. Pulsatility index is not a reliable predictor of intracranial pressure.

\section{Ultrasound versus invasive intracranial pressure measurement}

During the study, besides the invasive intracranial pressure measurement method, optic nerve sheath diameter and arterial and venous transcranial Doppler measurements were performed for all patients who required measurements of intracranial pressure. Invasive intracranial pressure measurement devices are 'gold standard' modalities [21] but due to the lack of neurosurgeons and/or contraindications, it is not always feasible [5, 19]. Arterial and venous transcranial ultrasound is fast and does not require specific dedicated hardware [8]. Ultrasonography device is available in the intensive care unit too [5]. Ultrasonography equipment is a hands-free tool for patients who need to measure intracranial pressure.

\section{Limitations}

Several limitations of the study have reported for examples, different types of brain injury patients were enrolled. Type of brain injury also has an effect on mortality. Effects of type of brain injury on mortality is not evaluated in multivariate analysis. There is a need for specialized training for image analysis of ultrasound. The threshold values for intracranial pressure and optic nerve sheath diameter are not well-defined for brain injuries [5]. Unlike an invasive method, ultra-sound has inter-and intra-observer variabilities.

\section{Conclusion}

Non-invasively measured straight sinus flow velocities, middle cerebral artery flow velocities, and optic nerve sheath diameter were correlated with invasively measured intracranial pressure. Optic nerve sheath diameter and intracranial pressure were independent parameters for mortality. Ultrasound measurement can be successfully used instead of invasive intracranial pressure measurement method in patients with brain injury. The large human trial is recommended to validate non-invasive techniques.

\section{Abbreviations}

FVd: Diastolic flow velocity; FVm: Mean flow velocity; FVs: Systolic flow velocity; STROBE: Strengthening the reporting of observational studies in epidemiology

\section{Acknowledgments}

Authors are thankful to all medical and non-medical staff of the Beijing Luhe Hospital, Affiliated to Capital Medical University, Beijing, China.

\footnotetext{
Authors' contributions

All authors have reviewed and approved the submitted manuscript for publication. JZ was the project administrator and contributed to the literature review, software, the data curation, and formal analysis of the study. JL contributed to the conceptualization, software, data curation, and literature review of the study. TY contributed to data curation, validation, software, and literature review of the study. YZ contributed to the formal analysis and literature review of the study, draft, review, and edited the manuscript for intellectual content. The author agrees to be accountable for all aspects of work ensuring integrity and accuracy.
} 


\section{Availability of data and materials}

The datasets used and analyzed during the current study available from the corresponding author on reasonable request.

\section{Ethics approval and consent to participate}

The protocol of the study (BLH/CMU/CL/25/17 dated 2 February 2017) had been approved by the Beijing Luhe Hospital human ethics committee. An informed consent form had been signed by all participating patients or patient caretakers regarding imaging modalities, clinical examination, invasive intracranial pressure measurement, and anesthesia. The study had adhered to the law of China, the strengthening the reporting of observational studies in epidemiology (STROBE) statement, and Declaration of Helsinki (V2008).

\section{Consent for publication}

An informed consent form had been signed by all participating patients or patient caretakers regarding the publication of the study in all formats of publication house including personal data of patients irrespective of time and language.

\section{Competing interests}

The authors declared that they have no competing interest or any the other competing interest regarding results and/or discussion reported in the research.

Received: 1 May 2019 Accepted: 24 June 2019

Published online: 05 July 2019

\section{References}

1. Badri S, Chen J, Barber J, Temkin NR, Dikmen SS, Chesnut RM, Deem S, Yanez ND, Treggiari MM. Mortality and long-term functional outcome associated with intracranial pressure after traumatic brain injury. Intensive Care Med. 2012:38:1800-9.

2. Chesnut RM, Temkin N, Carney N, Dikmen S, Rondina C, Videtta W, Petron G, Lujan S, Pridgeon J, Barber J, Machamer J, Chaddock K, Celix JM, Cherner $M$, Hendrix T. A trial of intracranial-pressure monitoring in traumatic brain injury. N Engl J Med. 2012;367:2471-81.

3. Strumwasser A, Kwan RO, Yeung L, Miraflor E, Ereso A, Castro-Moure F, Patel A, Sadjadi J, Victorino GP. Sonographic optic nerve sheath diameter as an estimate of intracranial pressure in adult trauma. J Surg Res. 2011;170:265-71.

4. Carney N, Totten AM, O'Reilly C, Ullman JS, Hawryluk GW, Bell MJ, Bratton SL, Chesnut R, Harris OA, Kissoon N, Rubiano AM, Shutter L, Tasker RC, Vavilala MS, Wilberger J, Wright DW, Ghajar J. Guidelines for the management of severe traumatic brain injury, fourth edition. Neurosurgery. 2017:80:6-15

5. Robba C, Cardim D, Tajsic T, Pietersen J, Bulman M, Donnelly J, Lavinio A, Gupta A, Menon DK, Hutchinson PJA, Czosnyka M. Ultrasound non-invasive measurement of intracranial pressure in neurointensive care: a prospective observational study. PLoS Med. 2017;14. https://doi.org/10.1371/journal. pmed.1002356.

6. Brain Trauma Foundation, American Association of Neurological Surgeons, Congress of Neurological Surgeons, Joint Section on Neurotrauma and Critical Care, AANS/CNS, Bratton SL, Chestnut RM, Ghajar J, McConnell Hammond FF, Harris OA, Hartl R, Manley GT, Nemecek A, Newell DW, Rosenthal G, Schouten J, Shutter L, Timmons SD, Ullman JS, Videtta W, Wilberger JE, Wright DW. Guidelines for the management of severe traumatic brain injury. IX. Cerebral perfusion thresholds. J Neurotrauma. 2007;24:S59-64.

7. Geeraerts T, Merceron S, Benhamou D, Vigué B, Duranteau J. Non-invasive assessment of intracranial pressure using ocular sonography in neurocritical care patients. Intensive Care Med. 2008;34:2062-7.

8. Zweifel C, Czosnyka M, Carrera E, de Riva N, Pickard JD, Smielewski P. Reliability of the blood flow velocity pulsatility index for assessment of intracranial and cerebral perfusion pressures in head-injured patients. Neurosurgery. 2012;71:853-61.

9. Ragauskas A, Bartusis L, Piper I, Zakelis R, Matijosaitis V, Petrikonis K, Rastenyte D. Improved diagnostic value of a TCD-based non-invasive ICP measurement method compared with the sonographic ONSD method for detecting elevated intracranial pressure. Neurol Res. 2014;36:607-14.
10. Ragauskas A, Matijosaitis V, Zakelis R, Petrikonis K, Rastenyte D, Piper I, Daubaris $\mathrm{G}$. Clinical assessment of noninvasive intracranial pressure absolute value measurement method. Neurology. 2012;78:1684-91.

11. Steiner $T$, Juvela $S$, Unterberg A, Jung C, Forsting M, Rinkel G, European Stroke Organization. European stroke organization guidelines for the management of intracranial aneurysms and subarachnoid haemorrhage. Cerebrovasc Dis. 2013:35:93-112.

12. Raj R, Siironen J, Skrifvars MB, Hernesniemi J, Kivisaari R. Predicting outcome in traumatic brain injury: development of a novel computerized tomography classification system (Helsinki computerized tomography score). Neurosurgery. 2014;75:632-46.

13. Robba C, Cardim D, Donnelly J, Bertuccio A, Bacigaluppi S, Bragazzi N, Cabella B, Liu X, Matta B, Lattuada M, Czosnyka M. Effects of pneumoperitoneum and Trendelenburg position on intracranial pressure assessed using different noninvasive method. Br J Anaesth. 2016;117:783-91.

14. Robba C, Bragazzi NL, Bertuccio A, Cardim D, Donnelly J, Sekhon M, Lavinio A, Duane D, Burnstein R, Matta B, Bacigaluppi S, Lattuada M, Czosnyka M. Effects of prone position and positive end-expiratory pressure on noninvasive estimators of ICP: a pilot study. J Neurosurg Anesthesiol. 2017; 29:243-50.

15. Oberfoell S, Murphy D, French A, Trent S, Richards D. Inter-rater reliability of sonographic optic nerve sheath diameter measurements by emergency medicine physicians. J Ultrasound Med. 2017;36:1579-84.

16. Treggiari MM, Schutz N, Yanez ND, Romand JA. Role of intracranial pressure values and patterns in predicting outcome in traumatic brain injury: a systematic review. Neurocrit Care. 2007:6:104-12.

17. Behrens A, Lenfeldt N, Ambarki K, Malm J, Eklund A, Koskinen LO. Transcranial Doppler pulsatility index: not an accurate method to assess intracranial pressure. Neurosurgery. 2010;66:1050-7.

18. Komut E, Kozacı N, Sonmez BM, Yılmaz F, Komut S, Yıldırım ZN, Beydilli I, Yel C. Bedside sonographic measurement of optic nerve sheath diameter as a predictor of intracranial pressure in ED. Am J Emerg Med. 2016;34:963-7.

19. Wakerley B, Yohana K, Luen Teoh H, Tan CW, Chan BP, Sharma VK. Noninvasive intracranial pressure monitoring with transcranial Doppler in a patient with progressive cerebral venous sinus thrombosis. J Neuroimaging. 2014;24:302-4

20. Frattalone AR, Stevens RD. Intracranial pressure and its surrogates. Intensive Care Med. 2011;37:1051-3.

21. Dubourg J, Javouhey E, Geeraerts T, Messerer M, Kassai B. Ultrasonography of optic nerve sheath diameter for detection of raised intracranial pressure: a systematic review and meta-analysis. Intensive Care Med. 2011;37:1059-68.

\section{Publisher's Note}

Springer Nature remains neutral with regard to jurisdictional claims in published maps and institutional affiliations.

Ready to submit your research? Choose BMC and benefit from:

- fast, convenient online submission

- thorough peer review by experienced researchers in your field

- rapid publication on acceptance

- support for research data, including large and complex data types

- gold Open Access which fosters wider collaboration and increased citations

- maximum visibility for your research: over $100 \mathrm{M}$ website views per year

At BMC, research is always in progress.

Learn more biomedcentral.com/submissions 